\title{
Preparation of Biopasalgira Pellet as A Candidate Media to Reduce Hardness of Water
}

\author{
Choirul Amri ${ }^{1}$ \\ \{choirul.amri@poltekkesjogja.ac.id ${ }^{1}$ \} \\ Department of Environmental Health, Poltekkes Kemenkes Yogyakarta, Jl. Tatabumi no 3 \\ Banyuraden, Gamping Sleman, Yogyakarta, Indonesia 55293 ${ }^{1}$
}

\begin{abstract}
Various efforts to reduce hardness continue to be carried out in the framework of providing water that meets the requirements. At the same time, it is necessary to strive for the development of Indonesia's natural resource potential which is possible to be a media candidate to reduce hardness, one of which is seaweed. Seaweed contains alginate polymer with carboxylic groups which in acidic conditions are insoluble in water and can bind calcium $(\mathrm{Ca})$ ions, so it is expected to be used as a media candidate to reduce hardness. In this study, the preparation of alginic acid was related to the ease of use and stability in water. The results showed that as a media candidate to reduce hardness, alginic acid could be prepared in the form of pellets. This alginic acid pellet has good stability at $\mathrm{pH}$ less than 7.
\end{abstract}

Keywords: alginic acid, pellet, stability, hardness.

\section{Introduction}

Various community complaints related to water hardness problems continue to emerge, ranging from physical water, crusting, to indirectly related to the impact on their health. Many efforts have been made to reduce water hardness, including heating, precipitation, sedimentation, and most commonly to reduce hardness by ion exchange. As an ion exchange medium zeolites and resins are often used.

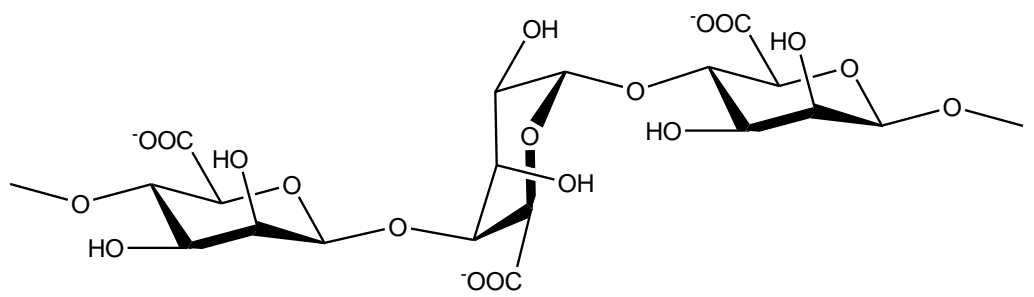

Fig. 1. Structure of alginates with block types of guluronic and manuronic bonds[1][2].

ICCSET 2018, October 25-26, Kudus, Indonesia

Copyright (C) 2018 EAI

DOI 10.4108/eai.24-10-2018.2280504 
Indonesia is rich in natural ingredients in addition to zeolites which need to be studied in relation to reducing water hardness. One of them is seaweed. Seaweed contains an alginate that can be separated from the parent structure. This alginate is known as a water-soluble polysaccharide consisting of $\beta$-D-Manuronates and $\alpha$-L-Guluronates which are linked to bonds (1-4)[3]. The alginate structure is presented in Figure 1.

In each alginate monomer there is a carboxylic group. Under acidic conditions, this group causes the formation of guluronic acid and or manuronic acid. This will cause intramolecular hydrogen bonds[3], and as a result form alginic acid formations (biopasalgira $=$ seaweed alginate acid biopolymer) which are not water soluble [4]. Hydrogen ions which are bound to carboxylic groups from this alginate can be replaced by hardness-causing metal ions, especially calcium (Ca), which is expected to reduce water hardness.

As a candidate for media to reduce hardness, this alginic acid polymer needs to be designed regarding its ease of use and stability. Therefore, in this study biopasalgira was designed in the form of pellets. Alginate polymers under acidic conditions are not soluble in water, so it is necessary to determine the stability of biopasalgira in water at varying water $\mathrm{pH}$. For this reason, this study will be reviewed.

\section{Experimental}

\subsection{Preparation of Biopasalgira Pellets}

Sodium alginate powder is made in the form of pellets with a pelletizer, then made alginic acid through soaking in $1 \mathrm{M} \mathrm{HCl}$ solution for 24 hours, and dried.

\subsection{Determination of The Stability of Biopasalgira Pellets}

Biopasalgira pellet stability was tested according to Amri et al (2015), namely by weighing the weight of the pellets (W1), then the pellets were soaked in water with a variety of $\mathrm{pH}(\mathrm{pH} 3,4,5$, .... 10) for 4 hours. The pellets were dried in an oven at $40^{\circ} \mathrm{C}$ for 24 hours, desiccated for 1 hour, then weighed (W2). Polymer stability (SP) at each $\mathrm{pH}$ was calculated using equation (1) [2].

$$
\mathrm{SP}=\left[1-\frac{\mathrm{W} 1-\mathrm{W} 2}{\mathrm{~W} 1}\right] \times 100
$$




\section{Result and Discussion}

Indonesian natural materials polymers continue to be used. In this paper, alginate seaweed polymer is developed as a media candidate to reduce hardness. Related to its ease of use, seaweed alginate polymer is made in the form of pellets as alginate acid (biopasalgira). To make this bioasalgira pellet, alginate which is still in the form of sodium alginate plus water to form a solid paste, then formed into pellets using a pellet printer. The printed pellets are soaked in 1 $\mathrm{M} \mathrm{HCl}$ solution for 24 hours until the pellets form a hard mass, then dried in the sun to dry. Alginate acid pellet formation was investigated using FTIR at $4000-500 \mathrm{~cm}^{-1}$ wave number. In Figure 2 presented the infrared (IR) spectra of sodium alginate and biopasalgira pellets.

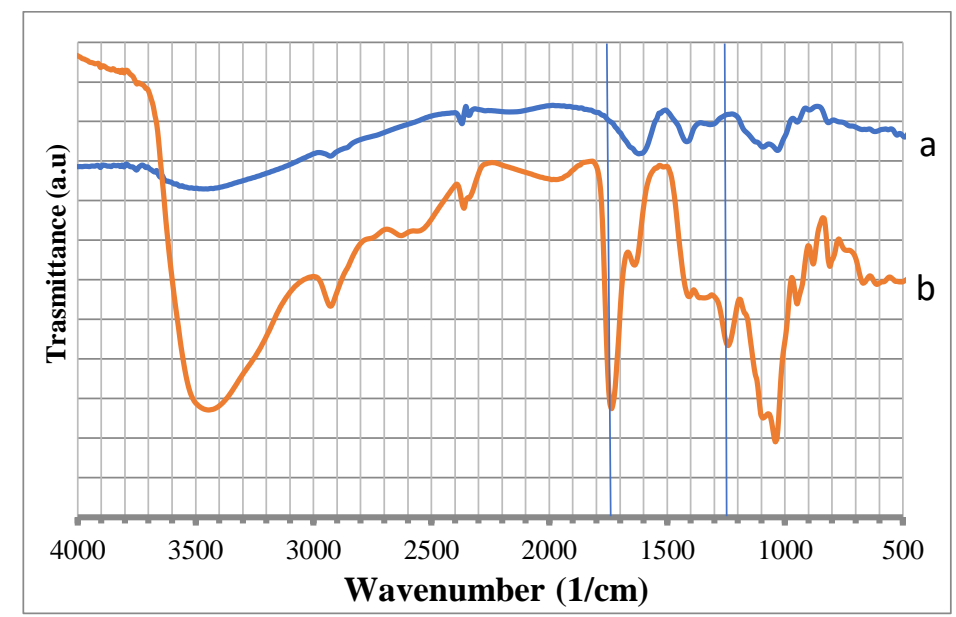

Fig. 2. FTIR spectra of (a) sodium alginate (a), and (b) biopasalgira pellets.

The carboxylic group in sodium alginate appeared at $1620 \mathrm{~cm}-1$, while in biopasalgira pellets at $1736 \mathrm{~cm}-1$. This peak shift of the carboxylic group indicates that the biopasalgira pellet has been formed. Taha et.al (2005) reported indications of alginate acid formation at a peak of $1752 \mathrm{~cm}-1$ [5]. Alginate in the form of alginic acid is reported to not dissolve in water. However, the use of biopasalgira pellets as a candidate of media to reduce hardness needs to be determined its stability.

The stability of biopasalgira pellets is determined in order to provide information on the $\mathrm{pH}$ of the water, how many alginate acid pellets can be used. In Figure 3 presented the stability of alginate acid pellets at various $\mathrm{pH}$ of water. Based on the stability test data, this alginic acid pellet has good stability at water $\mathrm{pH}<7$, so that the biopasalgira pellets can be used as a candidate of media to reduce water hardness which is less than $7 \mathrm{of} \mathrm{pH}$ or arranged in advance so that the water $\mathrm{pH}$ is less from 7. 


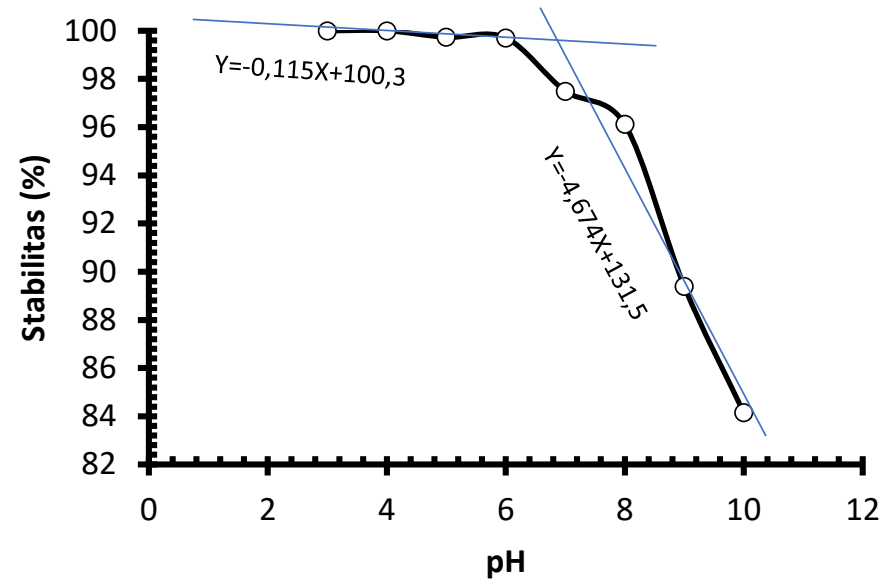

Fig. 3. Stability of biopasalgira pellets at various of $\mathrm{pH}$.

\section{Conclusion}

The use of seaweed alginate as a media candidate to reduce water hardness can be made in the form of biopasalgira pellets. Biopasalgira pellets have good stability at $\mathrm{pH}$ less than 7 .

\section{References}

[1] S. Kanakasabai, "Alginate Strings and Their Applications in Spinal Cord Regeneration," Drexel University College of Medicine, Drexel, 2005.

[2] C. Amri, D. Mudasir, Siswanta, and R. Roto, "Characterization of butanediol-alginate ester as candidate of hemodialysis membrane," Indones. J. Chem., vol. 2, 2015.

[3] A. W. Chan, "Controlled Synthesis of Stimuli-Responsive Network Alginate," Queen's University Kingston, Ontario, Canada, 2009.

[4] M. Davidovich and H. Bianco, "A Quantitative Analysis of Alginate Swelling," Carbohydr Polym, vol. 79, pp. 1020-1027, 2010.

[5] M. O. Taha, K. M. Aiedeh, Y. Al-Hiari, and H. Al-Khatib, "Synthesis of zinc-crosslinked thiolated alginic acid beads and their in vitro evaluation as potential enteric delivery system with folic acid as model drug," Pharmazie, vol. 60, no. 10. pp. 736-742, 2005. 